\title{
Tryptophan-derived beta-carboline
}

\section{Virginia L. Weber*, Michael S. Leonard}

Department of Chemistry, Washington \& Jefferson College

60 S Lincoln St, Washington, PA 15301

\section{Introduction}

Alkaloids, basic substances often isolated from plant sources, are important natural substances because they can exhibit ecological effects. For instance, it has been proposed that alkaloids aid plant defenses against phytophagous animals. ${ }^{1} \beta$-carbolines (Figure 1) are a specific subset of the alkaloid family exhibiting strong insecticidal activity and therefore have potential utility in crop protection.<smiles>c1ccc2c(c1)[nH]c1cnccc12</smiles>

Figure 1. Structure of the heterocycle $\beta$-carbolin

$\beta$-carbolines are known to have neurological repercussions in mammalian brains; thus, a hypothesis for possible insecticidal usage has been explored. The activity of $\beta$-carbolines stems from their ability to bind to benzodiazepine sites on the $G A B A_{A}$ receptor in the brain. Addition of a $\beta$-carboline to the benzodiazepine site induces shape change in the benzodiazepine receptor. This conformational change then causes the GABA receptor to bind GABA, aminobutyric acid, more tightly. The change in the GABA receptor encourages the associated chloride channel to open which induce a relaxation sensation. Benzodiazepines are a common class of drugs used as muscle relaxants. In contrast, $\beta$-carboline derivatives have been found to be agonists, antagonists, and inverse agonists. 2 Therefore, $\beta$-carbolines can have convulsive and anxiogenic effects or the opposite.

While investigating the reactivity of amino acids with ninhydrin, Heesing et al. discovered that the reaction of tryptophan with ninhydrin produced a yellow solid. The unexpected product was initially proposed to be a spirocyclic derivative of $1,2,3,4$ tetrahydro- $\beta$-carboline (I), but was later shown by $\mathrm{X}$-ray analysis to in fact be the yohimbanone II. The yield improvement was the in fact be the yohim of refinements to the product isolation. ${ }^{3}$
resula
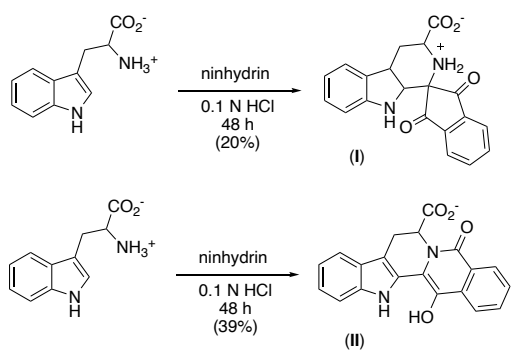

Over a decade later, Leonard et al. investigated the reaction between L-tryptophan methyl ester and ninhydrin and found that a Pictet-Spengler condensation product $\mathbf{2}$ could be isolated and converted in a separate step to the yohimbanone (3). This compound is named for its structural analogy to the naturally occurring alkaloid yohimbine, a member of the Rauwolfia alkaloid family. 4,5 The original reaction reported by Neuzil et al. used tryptophan and ninhydrin in $0.1 \mathrm{~N} \mathrm{HCl}$ and stirred for $48 \mathrm{~h}^{3}{ }^{3}$ Later, this work was expanded upon using Ltryptophan methyl ester in place of tryptophan, which allowed isolation of the Pictet-Spengler condensation product. This isolation is possible because the methyl ester provides a more stable synthetic intermediate. It was then found that heating the Pictet-Spengler condensation product at reflux with stannous chloride dihydrate in methanol for $22 \mathrm{~h}$ allowed for a novel rearrangement that produced the yohimbanone. ${ }^{6}$

This reaction sequence was also reproduced in the work described herein. The goals of this study were to repeat the known chemistry, improve upon recent progress, and generate one new analogue (6).

\section{Overall Synthesis}
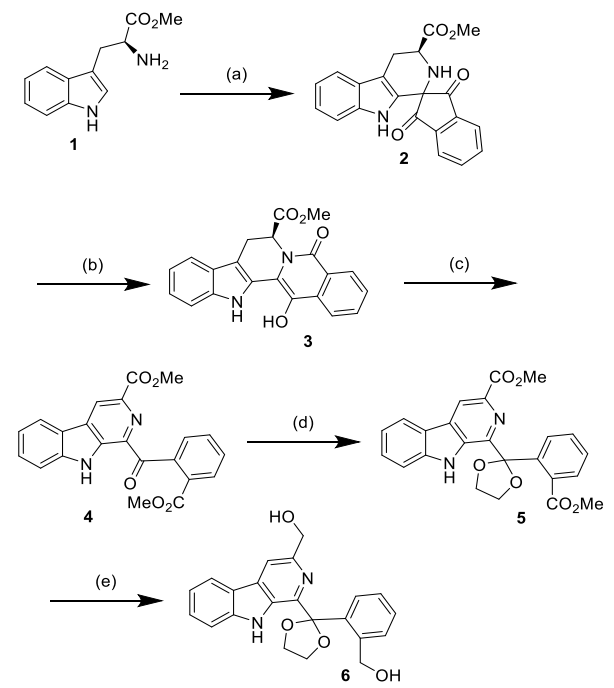

\begin{tabular}{|c|c|c|c|}
\hline Step & Reaction & Conditions & Percent Yield \\
\hline a & Pictet-Spengler Condensation & ninhydrin, $0.1 \mathrm{M} \mathrm{HCl}, 48 \mathrm{~h}$ & $66 \%$ \\
\hline b & Rearrangement to Yohimbanone & $\mathrm{SnCl}_{2} \cdot 2 \mathrm{H}_{2} \mathrm{O}, \mathrm{MeOH}$, reflux, 24 h & $91 \%$ \\
\hline c & Oxidative D-Ring Opening & $\mathrm{Cu}(\mathrm{OAc})_{2} \cdot \mathrm{H}_{2} \mathrm{O}, \mathrm{MeOH}, 24 \mathrm{~h}$ & $75 \%$ \\
\hline d & $\beta$-Carboline Derivatization & $\left(\mathrm{CH}_{2} \mathrm{OH}\right)_{2}, \mathrm{Cat} . \mathrm{TsOH}$, reflux, 48 h & $74 \%$ \\
\hline e & Novel $\beta$-Carboline Derivatization & $\mathrm{LiAlH}_{4}, \mathrm{THF}, 24 \mathrm{~h}$ & $87 \%$ \\
\hline & & & \\
& & & \\
\end{tabular}

\section{Discussion}

The purpose of this study was to synthesize a new $\beta$-carboline derivative for biological testing. First, the Pictet-Spengler condensation was replicated from a study performed by Leonard et al. Then earrangement to the yohimbanone, oxidative ing opening to provide beta-carboline 4 , and ketal formation (5) were performed. The reduction of $\mathbf{5}$ provided the previously unknown diol derivative 6, which was then successfully characterized. These compounds have bee subjected to biological testing. Future synthetic work will include hydrolysis of the acetal back to the ketone, which will reintroduce the carbonycontaining substituent at $\mathrm{C} 3$ of the $\beta$-carboline, which is known to enhance affinity for the benzodiazepine receptor.

\section{References} 1. Bouayad, N.; Rharrabe, K.; Lamhamdi, $\mathrm{M}$; 2. Cooper, S. J. Brain Researc, Bulletin. 1986,17 637.

3. Neuzil, E.; De Tinguy-Moreaud, E.; Precigoux, G.; Nguyen Ba, C.; Courseille, C. Chem. Biol. Med. 1990, 47-55. 4. Leonard, M. S.; Hauze, D. B.; Carroll, P. J.; Joullié, M. M. Tetrahedron 2003, 59, 6933-6936.

5. Tomasevich, L. L.; Kennedy, N. M.; Zitelli, S. M.; Hull, R. T. Gillen, C. R.; Lam, S. K.; Baker, N. J.; Rohanna, J. C.; Conley, J. Leonard, M. S. Tetrahedron Lett. $2007,48,599-602$. 6. Leonard, M. S.; Carroll, P. J.; Joullié, M. M. Synth. Commun. 2004, 34(5), 863-869.

\section{Acknowledgments}

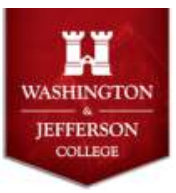

First and foremost, I would like to thank Dr. Michael S. Leonard for his continuous guidance and advice throughout this research study. Moreover, I would also like to thank the entire chemistry department at Washington \& Jefferson College for their encouragement and dedication to teaching throughout my academic career. 